\title{
Hubungan Kunjungan Trimester 1 dengan Screening Anemia pada Ibu Hamil di Era Peradaban Baru
}

\author{
Yuni Khoirul Waroh \\ Email: yunikhoirulwaroh@unipasby.ac.id \\ D III Kebidanan, Universitas PGRI Adi Buana Surabaya, Indonesia \\ Jl. Dukuh Menanggal XII/4 Surabaya \\ Telp/Fax. (031) 8281181
}

\begin{abstract}
Abstrak
Pandemi Covid-19 melahirkan adanya era peradaban baru yang dimana masyarakat diminta untuk berdaptasi terhadap kondisi pandemi ini. Hal ini juga berlaku pada pelayanan Kesehatan Ibu dan Anak khususnya pemeriksaan kehamilan. Penyebab kematian tertinggi di Indonesia tahun 2019 adalah karena perdarahan, yang dimana ini bisa dipengaruhi oleh rendahnya kadar hemoglobin atau yang lazim disebut anemia. Tujuan penelitian ini adalah untuk menganalisis hubungan kunjungan trimester 1 dengan screening anemia pada ibu hamil.Metode penelitian yang digunakan adalah cross sectional, dengan menggnakan media google form untuk pengisian angket dan screen shot buku KIA. Uji statistik pada penelitian ini menggunakan Pearson. Hasil penelitian menunjukkan tidak ada hubungan antara kunjungan trimester 1 dengan screening anemia yang didapatkan nilai uji statistik Pearson nilai sig $=0,189>0,05$ yang artinya tidak terdapat hubungan kunjungan trimester 1 dengan pemeriksaan kadar hemoglobin pada ibu hamil. Kesimpulan yang dapat diambil adalah bahwasannya meskipun sekarang memasuki era peradaban baru dimana ada beberapa daerah yang menerapkan Pembatasan Sosial Berskala Besar dan yang pada pelayanan Kesehatan Ibu dan Anak khususnya pemeriksaan pada kehamilan masih bisa dilaksanakan , kebijakan pemerintah pada era peradaban baru pada kunjungan Trimester 1 difokuskan pada screening kondisi kesehatan ibu terhadap komplikasi pada kehamilan, dan terutama menyangkut rujukan apabila terdapat komplikasi pada kehamilannya maupun penatalaksanaan pada ibu hamil dengan Covid-19, sehingga hal ini bisa mencegah penularan Covid-19.
\end{abstract}

Kata Kunci: kunjungan trimester 1; screening anemia; ibu hamil; era peradaban baru.

\begin{abstract}
The Covid-19 pandemic gave birth to a new civilization era where people were asked to adapt to this pandemic condition. This also applies to maternal and child health services, especially antenatal care. The highest cause of death in Indonesia in 2019 is due to bleeding, which can be influenced by low hemoglobin levels or what is commonly known as anemia. The purpose of this study was to analyze the relationship between first trimester visits and anemia screening in pregnant women. The research method used was cross sectional, using google form media to fill out questionnaires and screen shots of the MCH book. The statistical test in this study used Pearson. The results showed that there was no relationship between the first trimester visit and anemia screening, which was obtained by the Pearson statistical test value sig $=0.189>0.05$, which means that there was no relationship between the first trimester visit and the examination of hemoglobin levels in pregnant women. The conclusion that can be drawn is that even though we are now entering a new civilization era where there are several regions that implement Large-Scale Social Restrictions and which in Maternal and Child Health services, especially pregnancy examinations, can still be implemented, government policies in the new civilization era during the 1 st trimester visit are focused on screening of maternal health conditions for complications in pregnancy, and especially regarding referrals if there are complications in her pregnancy and management of pregnant women with Covid-19, so that this can prevent transmission of Covid-19.
\end{abstract}

Keywords: 1st trimester visited; anemia screening; pregnant women; new era of civilization. 
Jurnal Kebidanan Harapan Ibu Pekalongan

\section{Pendahuluan}

Kesehatan Ibu dan Anak masih menjadi prioritas utama pada masalah kesehatan di Indonesia. Sebelum ada pandemi Covid 19 Angka Kematian Ibu di Indonesia mencapai 305 per 100.000 kelahiran hidup. ${ }^{[1]}$

Meurut data profil Kesehatan Indonesia tahun 2019 target Angka Kematian Ibu tahun 2024 adalah 183/100.000 kelahiran hidup dan tahun 2030 diharapkan menjadi 131 per 100.000 kelahiran hidup, adapun penyebab kematian ibu terbanyak adalah perdarahan sebanyak 91.280 kasus., dan salah satu penyebab perdarahan adalah karena anemia dalam kehamilan. ${ }^{[2]}$

Proporsi kasus anemia pada ibu hamil tahun 2018 di Indonesia sebanyak $48,9 \%$. ${ }^{[1]}$

Data pemeriksaan kadar Hemoglobin pada perempuan usia 15-49 tahun selama masa kehamilan di Jawa Timur tahun 2018 sebanyak $56,16 \%$. ${ }^{[3]}$

Menurut laporan Riskesdas Jawa Timur 2018, capaian ANC K1 ideal kota Surabaya 89,35\%, ini sebelum ada pandemi Covid - 19.[3]

Pada saat ini untuk mengurangi tingginya angka kematian akibat persebaran Covid19 diberlakukan kebijakan Pembatasan Sosial Berskala Besar yang dimana dimaksudkan untuk mengurangi mobilitas manusia selaku agent penularan pada Covid$19 .^{[4]}$

Kebijakan PSBB juga berimbas pada terhentinya layanan kesehatan di tingkat masyarakat, yang dimana dari Laporan Kajian Cepat Kesehatan yang diadakan oleh Kementerian Kesehatan Republik Indonesia dan UNICEF tahun 2020 didapatkan data $75 \%$ pos pelayanan terpadu (Posyandu) tutup dan lebih dari $41 \%$ pelayanan ke rumah terhenti. Pada tingkat pos pelayanan terpadu (Posyandu) pelayanan antenatal care (ANC) terhenti sebanyak $46 \%{ }^{[5]}$

Hal tersebut di atas yang menjadi landasan peneliti untuk melakukan penelitian ini.

\section{Metode Penelitian}

Jenis penelitian ini observasi analitik dengan menggunakan metode cross sectional. Data didapatkan melalui wawancara kepada responden dengan menggunakan google form yang berisi angket dan screen shot dari buku KIA.

Penelitian ini dilaksanakan di Kelurahan Siwalankerto, Kecamatan Wonocolo Kota Surabaya pada bulan Maret 2020Januari 2021

Pengambilan sampel pada penelitian ini mengginakan probability sampling. Besar sampel pada penelitian ini sebesar $56 \mathrm{ibu}$ hamil.

Uji statistik pada penelitian ini menggunakan Pearson.

\section{Hasil dan Pembahasan}

a. Data Umum

1) Umur Ibu

Tabel 1 Distribusi Frekuensi Umur Ibu Hamil di Kelurahan Siwalankerto

\begin{tabular}{ccc}
\hline Umur Ibu & Frekuensi & $\begin{array}{c}\text { Presentase } \\
(\mathbf{\%})\end{array}$ \\
\hline $\begin{array}{l}15-20 \\
\text { tahun }\end{array}$ & 0 & 0,0 \\
$21-35$ & 56 & 100,0 \\
tahun & & \\
$\begin{array}{l}36-45 \\
\text { tahun }\end{array}$ & 0 & 0,0 \\
\hline Jumlah & $\mathbf{5 6}$ & $\mathbf{1 0 0}$ \\
\hline \multicolumn{2}{l}{ Sumber: Data Primer 2020 }
\end{tabular}

Dari tabel menunjukkan bahwa seluruhnya umur ibu hamil di Kelurahan Siwalankerto berumur 
Jurnal Kebidanan Harapan Ibu Pekalongan

21-35 tahun sebanyak $56 \mathrm{ibu}$ $(100,0 \%)$

\section{2) Pendidikan}

Tabel 2 Distribusi Frekuensi Pendidikan Ibu Hamil di Kelurahan Siwalankerto

\begin{tabular}{ccc}
\hline $\begin{array}{c}\text { Pendidikan } \\
\text { Ibu }\end{array}$ & Frekuensi & $\begin{array}{c}\text { Presentase } \\
\mathbf{( \% )}\end{array}$ \\
\hline Dasar & 0 & 0,0 \\
Menengah & 16 & 28,6 \\
Perguruan & 40 & 71,4 \\
Tinggi & & \\
\hline Jumlah & $\mathbf{5 6}$ & $\mathbf{1 0 0}$ \\
\hline Sumber Data Primer 2020 &
\end{tabular}

Sumber : Data Primer 2020

Dari tabel menunjukkan bahwa hampir setengahnya pendidikan ibu hamil di Kelurahan Siwalankerto adalah pendidikan tinggi sebanyak $40 \mathrm{ibu}(71,4 \%)$

\section{3) Pekerjaan}

Tabel 3 Distribusi Frekuensi Pekerjaan Ibu Hamil di Kelurahan Siwalankerto

\begin{tabular}{ccc}
\hline $\begin{array}{c}\text { Pekerjaan } \\
\text { Ibu }\end{array}$ & Frekuensi & $\begin{array}{c}\text { Presentase } \\
(\mathbf{\%})\end{array}$ \\
\hline IRT & 2 & 3,5 \\
Wiraswasta & 21 & 37,5 \\
Swasta & 26 & 46,5 \\
PNS & 7 & 12,5 \\
\hline Jumlah & $\mathbf{5 6}$ & $\mathbf{1 0 0}$ \\
\hline
\end{tabular}

Sumber : Data Primer 2020

Dari tabel menunjukkan bahwa hampir setengahnya pekerjaan ibu hamil di Kelurahan Siwalankerto adalah swasta sebanyak $26 \mathrm{ibu}$ $(46,5 \%)$.

\section{4) Paritas}

Tabel 4 Distribusi Frekuensi Paritas Ibu Hamil di Kelurahan Siwalankerto

\begin{tabular}{ccc}
\hline Paritas Ibu & Frekuensi & $\begin{array}{c}\text { Presentase } \\
\text { (\%) }\end{array}$ \\
\hline Primigravida & 28 & 50,0 \\
Multigravida & 28 & 50,0 \\
Grandemultigravida & 0 & 0,0 \\
\hline Jumlah & $\mathbf{5 6}$ & $\mathbf{1 0 0}$ \\
\hline Sumber : Data Primer 2020 \\
Dari tabel menunjukkan bahwa \\
berimbang paritas ibu hamil di \\
Kelurahan Siwalankerto antara \\
yang primigravida dan \\
multigravida
\end{tabular}

b. Data Khusus

1) Kunjungan Trimester 1

Tabel 5 Distribusi Frekuensi Kunjungan Ibu Hamil Trimester 1 di Kelurahan Siwalankerto

\begin{tabular}{ccc}
\hline $\begin{array}{c}\text { Kunjungan } \\
\text { Trimester 1 }\end{array}$ & Frekuensi & $\begin{array}{c}\text { Presentase } \\
(\%)\end{array}$ \\
\hline Tidak Ideal & 32 & $57,1 \%$ \\
Ideal & 24 & $42,9 \%$ \\
\hline Jumlah & $\mathbf{5 6}$ & $\mathbf{1 0 0}$ \\
\hline Sumber : Data Primer 2020 &
\end{tabular}

Dari tabel menunjukkan bahwa lebih dari setengahnya ibu hamil di Kelurahan Siwalankerto melakukan kunjungan Trimester 1 ideal sebanyak 32 ibu hamil $(57,1 \%)$.

Menurut Anung Ahadi, et al (2020), ibu hamil termasuk dalam kelompok rentan terkena Covid 19, kerna pada saat hamil kondisi keshatan mengalami penurunan kesehatan parsial disebabkan adaptasi tubuh terhadap kehamilan.perubahan fisiologis dan imunologis pada kehamilan dapat meningkatkan resiko komplikasi obstetrik dan infeksi pernafasan. ${ }^{[6]}$

Menurut Depkes 2020, pelayanan Ante Natal Care (ANC) 
Jurnal Kebidanan Harapan Ibu Pekalongan

selama masa pandemi minimal $6 \mathrm{x}$, dengan frekuensi pemeriksaan $2 \mathrm{x}$ selama Trimester 1, $1 \mathrm{x}$ di trimester 2 , dan $3 \mathrm{x}$ di trimester 3. Minimal 2x diperiksa oleh dokter spesialis kandungan untuk melakukan skrining. ${ }^{[7]}$

Dalam penelitian ini didapatkan lebih dari setengahnya ibu hamil di Kelurahan Siwalankerto melakukan kunjungan Trimester 1 ideal, yang diartikan bahwa ibu hamil melakukan pemeriksaan kehamilannya selama Trimester 1 minimal 2x. Hal ini bisa diartikan karena ibu hamil tinggal di perkotaan akses pelayanan kesehatan relatif masih lebih muda, meskipun dengan pembatasan physical distancing.

\section{2) Screening Anemia}

Tabel 6 Distribusi Frekuensi Screening Anemiadi Kelurahan Siwalankerto

\begin{tabular}{ccc}
\hline $\begin{array}{c}\text { Screening } \\
\text { Anemia }\end{array}$ & Frekuensi & $\begin{array}{c}\text { Presentase } \\
(\%)\end{array}$ \\
\hline Dilakukan & 43 & $76,8 \%$ \\
Tidak & 13 & $23,2 \%$ \\
Dilakukan & & \\
\hline Jumlah & $\mathbf{5 6}$ & $\mathbf{1 0 0}$ \\
\hline
\end{tabular}

Sumber : Data Primer 2020

Dari tabel menunjukkan bahwa hampir seluruhnya ibu hamil di Kelurahan Siwalankerto melakukan screening anemia sebanyak 43 ibu hamil (76,8\%).

Menurut B. Sasangka and T. Ratnaningsih (2019) salah satu sarana untuk screening defisiensi zat besi pada ibu hamil adalah dengan melakukan pemeriksaan kadar content hemoglobin reticulocyte $(\mathrm{CHr})$.[8]

Menurut Herlambang, A. D. Fitri, and A. Puspasari (2018) menyatakan bahwa dengan intervensi dan meningkatkan edukasi pada ibu hamil diharapkan terjadi penurunan pada kasus anemia. ${ }^{[9]}$

Dalam penelitian ini didapatkan data bahwa hampir seluruhnya ibu hamil melakukan pemeriksaan kadar hemoglobin, hal ini sesuai dengan pendapat para pakar, bahwasannya dengan dilakukan screening sedini mungkin, penatalaksanaan komplikasi yang disebabkan karena anemia bisa ditekan , sehingga angka morbiditas dan mortalitas bisa berkurang.

\section{3) Hubungan Kunjungan Trimester 1 dengan Screening Anemia}

Tabel 7 Uji statistik hubungan Kunjungan Trimester 1 dengan Pemeriksaan Kadar Hemoglobin

\begin{tabular}{|c|c|c|c|}
\hline & 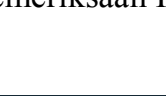 & K1 & $\begin{array}{l}\text { Screening } \\
\text { Anemia }\end{array}$ \\
\hline \multirow[t]{3}{*}{ K1 } & $\begin{array}{l}\text { Pearson } \\
\text { Correlation }\end{array}$ & 1 & .180 \\
\hline & $\begin{array}{l}\text { Sig. (2- } \\
\text { tailed) }\end{array}$ & & .189 \\
\hline & $\mathrm{N}$ & 55 & 55 \\
\hline \multirow[t]{3}{*}{$\begin{array}{l}\text { Screening } \\
\text { Anemia }\end{array}$} & $\begin{array}{l}\text { Pearson } \\
\text { Correlation }\end{array}$ & .180 & 1 \\
\hline & $\begin{array}{l}\text { Sig. (2- } \\
\text { tailed) }\end{array}$ & .189 & \\
\hline & $\mathrm{N}$ & 55 & 55 \\
\hline
\end{tabular}

Sumber : Data Primer 2020

Dari tabel menunjukkan bahwa dari uji statistik Pearson menunjukkan bahwa nilai sig $=$ $0,189>0,05$ yang artinya tidak terdapat hubungan kunjungan trimester 1 dengan pemeriksaan kadar hemoglobin pada ibu hamil di Kelurahan Siwalankerto

Menurut S. Natalia, S. Sumarmi, and S. R. Nadhiroh (2017) menunjukkan bahwacakupan pemberian tablet Fe kepada ibu hamil melalui pelayanan ANC tidak 
Jurnal Kebidanan Harapan Ibu Pekalongan

menggambarkan besar kecilnya prevalensi anemia ibu hamil karena yang mempengaruhi anemia meliputi banyak faktor seperti bioavaibilitas zat besi, dan kepatuhan ibu hamil mengonsumsi zat besi. ${ }^{[10]}$

Menurut A. Aziz et al.(2020) menyatakan pelayanan antenatal care selama pandemi bisa dengan menggunakan telehealth yang dimana bisa dilakukan pada beberapa kasus yang patologis, antara lain: preeklampsia, diabetes gestasional, penyakit cardiovasculer pada ibu, penyakit neurologis, riwayat persalinan prematur, gangguan pertumbuhan intrauterine, kelainan kongenital, anemia, dll. Meskipun kunjungan virtual telehealth tidak sepenuhnya menggantikan pertemuan langsung selama kunjungan ante natal care, namun kunjungan tersebut menawarkan cara untuk mengurangi kemungkinan pasien dan penyedia terpapar COVID-19 sambil memberikan pengujian dan layanan yang terkonsolidasi secara langsung. Telehealth dapat mengurangi paparan virus korona selama kehamilan. Telehealth harus disesuaikan untuk ibu hamil berisiko tinggi $\left[{ }^{11]}\right.$

Menurut $\mathrm{H}$. Wu et al(2020) asuhan antenatal online akan menjadi alternatif yang lebih disukai bagi para ibu hamil ini karena dapat memberikan informasi terkait kehamilan dan konsultasi klinik jarak jauh. Selain itu, asuhan antenatal online dapat membantu menyediakan layanan medis yang relatif ekonomis dan mengurangi ketidaksetaraan perawatan kesehatan karena kemudahan dan efektivitas biaya, terutama di negara atau wilayah berkembang.
Namun, beberapa wanita hamil akan meragukan keandalan informasi online tersebut. Oleh karena itu, penting untuk memastikan kualitas dan keamanan layanan online dan membangun rasa saling percaya yang stabil antara ibu hamil, penyedia layanan kebidanan, dan teknologi terkait program online. ${ }^{12]}$

Dalam penelitian ini didapatkan data bahwa tidak ada hubungan antara Kunjungan Antenatal Trimester 1 dengan Screening Anemia. Hal ini dimungkinkan meskipun ibu sudah melakukan pemeriksaan Ante Natal Care ideal, akan tetapi ibu tidak bisa mendapatkan pelayanan screening anemia secara optimal. Hal ini bisa disebabkan karena selama pandemi Covid -19 ini petugas kesehatan melakukan asuhan seminimal mungkin, guna mencegah penularan Covid-19. Alternatif yang bisa digunakan untuk tetap melakukan pengawalan pada kesehatan ibu hamil bisa dengan menggunakantelehealth dengan media sosial, salah satunya bisa dengan menggunakan group whats-up yang untuk melakukan pengawalan terutama pada kehamilan berisiko tinggi.

\section{Kesimpulan}

Kesimpulan yang dapat
diambil adalah bahwasannya
meskipun sekarang memasuki era
peradaban baru dimana ada
beberapa daerah yang menerapkan
Pembatasan Sosial Berskala Besar
(PSBB) pada beberapa kota yang
berimbas pada pelayanan Kesehatan
Ibu dan Anak khususnya
pemeriksaan pada kehamilan masih
bisa dilaksanakan, akan tetapi tidak


Jurnal Kebidanan Harapan Ibu Pekalongan

berhubungan dengan screening pada anemia, kebijakan pemerintah pada era peradaban baru pada kunjungan Trimester 1 difokuskan pada screening kondisi kesehatan ibu terhadap komplikasi pada kehamilan, dan terutama menyangkut rujukan apabila terdapat komplikasi pada kehamilannya maupun penatalaksanaan pada ibu hamil dengan Covid-19, untuk penanggulanagan masalah Kesehatan Ibu dan Anak terutama dalam masa kehamilan dibutuhkan kerjasama lintas sektoral.

\section{Daftar Pustaka}

[1] Riskesdas 2018, "HASIL UTAMA RISKESDAS 2018 Kesehatan," pp. 20-21, 2018.

[2] Kemenkes RI, Profil Kesehatan Indonesia Tahun 2019, vol. 42, no. 4, 2019.

[3] Riskesdas, Laporan Provinsi Jawa Timur Riskesdas 2018, 2019.

[4] Presiden Republik Indonesia, "Peraturan Pemerintah Nomor 21 Tahun 2020 tentang Pembatasan Sosial Berskala Besar Dalam Rangka Percepatan Penanganan Coronavirus Disease 2019/COVID-19," vol. 2019, no. 022868 , p. 8, 2020.

[5] Kemenkes and UNICEF, "Laporan Kajian Cepat Kesehatan: Latar Belakang Layanan kesehatan esensial pada masa pandemi COVID19 di Indonesia," pp.1-8, 2020.
[6] A. A. Pradana, C. Casman, and N. Nur'aini, "Pengaruh Kebijakan Social Distancing pada Wabah COVID-19 terhadap Kelompok Rentan di Indonesia," $J . \quad$ Kebijak. Kesehat. Indones. JKKI, vol. 9, no. 2, pp. 61-67, 2020, [Online].

https://jurnal.ugm.ac.id/jkki/art icle/view/55575.

[7] Kemenkes RI, Pedoman pelayanan antenatal, persalinan, nifas, dan bayi baru lahir di Era Adaptasi Baru, 2020.

[8] B. Sasangka and T. Ratnaningsih, "Reticulocyte hemoglobin content $(\mathrm{CHr})$ untuk skrining defisiensi besi pada ibu hamil," J. Gizi Klin. Indones., vol. 16, no. 1, p. 40, 2019, doi: 10.22146/ijcn.27387.

[9] Herlambang, A. D. Fitri, and A. Puspasari, "Skrinning dan Tatalaksana Anemia Pada Ibu Hamil di Wilayah Kerja Puskesmas Muaro Kumpeh dan Klinik Mer-c Jambi," Med. (Medical Dedication), vol. 1, no. 1, pp. 1-7, 2018.

[10] S. Natalia, S. Sumarmi, and S. R. Nadhiroh, "Cakupan Anc Dan Cakupan Tablet $\mathrm{Fe}$ Hubungannya Dengan Prevalensi Anemia Di Jawa Timur," Media Gizi Indones., vol. 11 , no. 1, p. 70, 2017, doi: 10.20473/mgi.v11i1.70-76.

[11] A. Aziz et al., "Telehealth for High-Risk Pregnancies in the Setting of the COVID-19 Pandemic," Am. J. Perinatol., 2020, doi: 10.1055/s-00401712121. 
Jurnal Kebidanan Harapan Ibu Pekalongan

[12] H. Wu et al., "Online antenatal care during the COVID-19 pandemic: Opportunities and challenges," Journal of Medical Internet Research, 2020, doi: 10.2196/19916. 